\title{
Acceptability of Height Measuring Equipment of Different Materials among Community Nutrition and Health Workers and Parents in Laguna Province, Philippines
}

\author{
Maria Theresa M. Talavera, RND, DrPH, ${ }^{1}$ Normahitta P. Gordoncillo, RND, PhD, ${ }^{1}$ \\ Nancy A. Tandang, $\mathrm{PhD}^{2}$ and Divine Grace C. Domingo, RND, MSc ${ }^{1}$ \\ ${ }^{1}$ Institute of Human Nutrition and Food, College of Human Ecology, University of the Philippines Los Baños \\ ${ }^{2}$ Institute of Statistics, College of Arts and Sciences, University of the Philippines Los Baños
}

\begin{abstract}
Objectives. This study aimed to determine the acceptability of four height/length boards as measuring equipment, (1) NNC wooden height board (HB), (2) Allen's stick, (3) aluminum-acrylic height board, and (4) stadiometer, from the perspective of the community nutrition and health workers (CNHWs) and mothers/caregivers.

Methods. The study was conducted in two municipalities in the province of Laguna, Philippines. Respondents were $12 \mathrm{CNHWs}$ and 22 parents/guardians of randomly selected children ages 1-5 years. Focus group discussions were also conducted among CNHWs to determine their perceptions, experiences, and feedback on the use of the equipment. Parents/guardians were interviewed about their views on the acceptability of the equipment.

Results and Conclusion. In the urban area, Allen's stick was most favored by end-users, while in the rural area, the NNC wooden HB was the most acceptable. Meanwhile, guardians preferred the aluminum-acrylic HB in the rural area and Allen's stick in the urban area. It was concluded that the use of height boards to measure the height or length of children was acceptable to both CHNWs and parents. CHNWs preferred the stadiometer for height measurement and Allen's stick for length measurement. In contrast parents/guardians preferred the aluminumacrylic HB and Allen's stick as these were deemed non-threatening, culturally acceptable, safe, comfortable for the children, and the procedures were easily understood.
\end{abstract}

Key Words: height board, community nutrition workers, children under five

\section{INTRODUCTION}

Nutritional anthropometry is commonly used to assess the nutritional status of children. Weight and height are measured to monitor the growth of children. In particular, the height or length of children provides information on stature and is interpreted using height/length-for-age index. ${ }^{1}$ Height measurement is essential because studies, such as that of van Hinke et al., showed that taller children have higher IQ, performed better in school, and were less likely to have behavioral problems. ${ }^{2}$

Several measuring equipment are made up of different materials available to measure height/length. Factors to consider in choosing which measuring equipment to use are

Corresponding author: Maria Theresa M. Talavera, RND, DrPH Institute of Human Nutrition and Food College of Human Ecology University of the Philippines Los Baños Email:mmtalavera@up.edu.ph cost, portability, and weight. In addition, the acceptability of the equipment to the users (i.e., health and nutrition workers) who will carry the equipment and the subjects (i.e., children and their mothers) should also be considered so that 
protocols will be followed, make accurate measurements, and allow children to be measured. Manual measurement of length or height for many children is time-consuming and tiring if done in a community setting. ${ }^{3,4}$ Only a few studies have looked at how the intended users (community nutrition and health workers) and beneficiaries (children and their mothers) would accept the inclusion of a new measurement, such as height or length, in growth monitoring activities. ${ }^{5,6}$

For more than two decades, weight has been the only parameter used in the national program known as Operation Taimbang (OPT) to measure children's nutritional status. In 2012, height/length measurement was included in the Department of Health Operation Timbang Plus (OPT Plus) program as one of the essential anthropometric data that need to be collected. ${ }^{7}$ The National Nutrition Council (NNC) Governing Board approved its implementation nationwide. ${ }^{8}$ The same resolution called for the use of standard measuring procedures and equipment to ensure the accuracy and reliability of the measurements. In this regard, the NNC distributed wooden height/length boards and stainless steel rulers to local government units to support the implementation of OPT Plus. While the NNC Governing Board recommended the use of wooden height/length board for assessing linear growth of children 0-71 months old, the communities were instructed to assess other possible materials like plastic and metal, preferably light materials, to be used in the fabrication of the height boards. ${ }^{8}$

Three height/length measuring equipment, 1) Allen's stick, 2) aluminum-acrylic height board (HB), and 3) stadiometer, were identified as possible alternatives to the NNC wooden height board (HB). This study aimed to determine the acceptability of these three height/length boards as measuring equipment from the perspective of the community nutrition and health workers and mothers/ caregivers.

\section{MATERIALS AND METHODS}

\section{Study design and sites}

The study, which used a mixed-method of quantitative and qualitative research design, was conducted in two municipalities in the province of Laguna, Philippines. Study sites were selected based on population, income, and accessibility. This study was part of a field trial of height measuring equipment in the same municipalities. The municipality of Sta. Rosa was selected to represent urban communities, while Bay, represented rural communities.

\section{Study participants}

Twelve Community Nutrition and Health Workers (CNHWs), who were members of the OPT Plus team and primary users of the height/length boards, served as participants in the study. In addition, twenty-two (22) parents/guardians of randomly selected children ages 1-5 years in each municipality, were interviewed regarding their experience while having their children's height/ length measured using the four measuring equipment. Parents/guardians were present during the conduct of the measurements.

\section{Height boards}

The four height boards are made up of different materials: (1) NNC wooden HB is made of wood; (2) Allen's Stick is made of aluminum and composite plastic; (3) aluminumacrylic HB of aluminum and acrylic; and (4) stadiometer of medical plastic. Allen's stick was developed by a local health officer; aluminum-acrylic HB by an expert in early warning and surveillance system; while the stadiometer (SECA brand) is commercially available. The community nutrition and health workers used all length/height measuring tools. The UNICEF (1986), WHO (2008) standard procedures, and the NNC OPT Plus Guidelines to measure height/length of children were carefully followed. ${ }^{9}$ Recumbent length was measured for children less than two years old while standing height was measured for children two years and older.

\section{Experiences and feedback on the use of equipment}

Two focus group discussions were conducted with the CNHWs as participants to determine their perceptions, experiences, and feedback on the use of equipment. The guide questions were pretested in a community similar to the study sites. The guide questions focused on the preparation of the equipment, time spent in calibration, ease of reading measurements, time spent in taking a measurement, ease in using the equipment, ease of transport (weight of the equipment), safe use of equipment, position of the end-user in reading the measurement, number of persons needed to take a measurement, number of steps to follow in measuring, ease of reading when child is struggling, number of detachable parts, ease of maintaining the equipment, ease in storing the equipment, problems encountered in calibrating, problems encountered in measuring child, problems in maintaining the equipment, problems in storing the equipment, and preference to continue height/length measurement. On the other hand, parents/guardians were interviewed about their views on allowing their children to be measured, preferred measurer, number of times the children's height/length were measured, and the manner of giving height/length, and nutritional status information to mother/parents. In addition, their opinions on the acceptability of the equipment, safety, comprehensibility of procedures, and comfort experienced by the child during measurement, were determined.

\section{Data analyses}

Appropriate descriptive statistics were generated, and percentage distributions were constructed to describe the characteristics of the parents/guardians and end-users. A comparison of the mean scores of the community nutrition and health workers (CNHWs) between rural and urban study sites was performed using $t$-test for independent 
samples. Repeated measures Analysis of Variance (ANOVA) was used to compare the four types of equipment based on various characteristics scored by the community nutrition and health workers. Thematic analysis was done to determine the perceptions, experiences, and feedback on the use of the equipment.

\section{Adherence to ethical requirements}

The National Ethics Committee of the Philippine Council for Health Research and Development (PCHRD) of the Department of Science and Technology (DOST) granted ethical clearance NEC Code 2017-001 for the study on March 17, 2017.

\section{RESULTS, DISCUSSION AND CONCLUSION}

Height is generally determined during early childhood, and it reflects the combined influence of early childhood environment, including nutrition, disease insults, and investments in health during pregnancy and the first few years of life. ${ }^{10}$ The Philippine government, through the National Nutrition Council (NNC), recognizes the importance of height assessment in growth monitoring among children 0-71 months, thus the inclusion of height and length measurement in annual mass weighing (OPT Plus). The need for the acceptable height measurement equipment among end-users and parents would facilitate the collection of accurate data on the height of children and will result in a higher coverage rate for the OPT Plus program.

\section{Profile of study participants}

On average, CNHWs from Bay were a bit older than those from Sta. Rosa, with a mean age of 49 and 45 years old, respectively. Some have served the barangay as health workers for over a decade. CNHWs from Bay (mean=7 years) have been in service longer than those from Sta. Rosa (mean $=5$ years). It was recorded during the focus group discussion that CNHWs from Sta. Rosa had attended the past 3-day proper height/length measurement training conducted by the National Nutrition Council (NNC). Similarly, most CNHWs from the rural area were adequately trained as well. Many were high school graduates, comprising 50\% and $83 \%$ from Bay and Sta. Rosa, respectively. A total of forty (40) children, 0-71 months old, were included in the study. The youngest child was four (4) months old from Bay, while the oldest was sixty-six (66) months old from Sta. Rosa. Males outnumbered females in both sites. Parents/guardians from Bay and Sta. Rosa had a mean age of 35.7 and 38.6 years, respectively. Around $55 \%$ and $32 \%$, respectively, were high school graduates. The mean number of children was approximately two (2) in both areas.

\section{Accuracy of the height measuring equipment}

Allen's stick, aluminum-acrylic, and stadiometer in measuring children's height were analyzed, comparing the three equipment against the NNC wooden height board as reference equipment. For children $0-23$ months residing in the rural area, the mean reading using Allen's stick was significantly higher than that of NNC's wooden height board. The aluminum-acrylic had a significantly lower mean height reading than the NNC wooden height board measurement. Allen's stick may be considered accurate in the urban setting with its mean length reading not significantly different from the mean length obtained using the NNC wooden height board (Table 1).

In measuring the height of children 24-71 months old in rural area, Allen's stick and stadiometer were found to be not significantly different from the NNC wooden height board, but significantly different from aluminum-acrylic. The same results were observed in the urban area, Allen's stick and stadiometer produced a mean height reading not significantly different from the NNC wooden height board, in which the most accurate one (relative to the NNC wooden height board) was the stadiometer (Table 1).

\section{Community nutrition and health workers' expe- riences and feedback on measuring equipment}

Table 2 shows the mean score (with 10 as the highest) given by the CNHWs to each equipment based on several characteristics, with the $\mathrm{NNC}$ wooden $\mathrm{HB}$ receiving the highest score. However, in terms of the number of steps in performing the procedure, ease in reading, number of parts removed, problems encountered during calibration, the CNHWs found aluminum-acrylic $\mathrm{HB}$ as the most appropriate equipment. Allen's stick, on the other hand, was preferred in discrete carrying of equipment, receiving the highest mean score in terms of the willingness of the BNS (Barangay Nutrition Scholar) to continue using the tool. In terms of overall acceptability, NNC wooden HB was the most preferred, followed by aluminum-acrylic HB.

Table 1. Inter-equipment accuracy of height/length measurement (as measured) by health workers) of children 0-71 months in rural and urban areas, Bay and Sta. Rosa, Laguna, Philippines

\begin{tabular}{|c|c|c|c|c|}
\hline \multirow{2}{*}{ Equipment } & \multicolumn{2}{|c|}{ Rural } & \multicolumn{2}{|c|}{ Urban } \\
\hline & Mean & $p^{*}$ & Mean & $p^{*}$ \\
\hline \multicolumn{5}{|l|}{$0-23$ months old } \\
\hline $\begin{array}{l}\text { Allen's stick vs. } \\
\text { Wooden HB }\end{array}$ & $\begin{array}{l}72.7 \\
72.0\end{array}$ & 0.035 & $\begin{array}{l}83.8 \\
83.5\end{array}$ & 0.171 \\
\hline $\begin{array}{l}\text { Aluminum-acrylic vs. } \\
\text { NNC wooden HB }\end{array}$ & $\begin{array}{l}71.3 \\
72.0\end{array}$ & 0.047 & $\begin{array}{l}83.0 \\
83.5\end{array}$ & 0.034 \\
\hline \multicolumn{5}{|l|}{ 24-71 months old } \\
\hline $\begin{array}{l}\text { Allen's stick vs. } \\
\text { NNC wooden HB }\end{array}$ & $\begin{array}{l}97.2 \\
96.9\end{array}$ & 0.139 & $\begin{array}{l}99.5 \\
99.1\end{array}$ & 0.060 \\
\hline $\begin{array}{l}\text { Aluminum-acrylic vs. } \\
\text { NNC wooden HB }\end{array}$ & $\begin{array}{l}96.6 \\
96.9\end{array}$ & 0.008 & $\begin{array}{l}98.8 \\
98.2\end{array}$ & 0.003 \\
\hline $\begin{array}{l}\text { Stadiometer vs. } \\
\text { NNC wooden HB }\end{array}$ & $\begin{array}{l}97.1 \\
96.9\end{array}$ & 0.434 & $\begin{array}{l}99.2 \\
99.1\end{array}$ & 0.302 \\
\hline
\end{tabular}

*significant at $p<0.05$ 

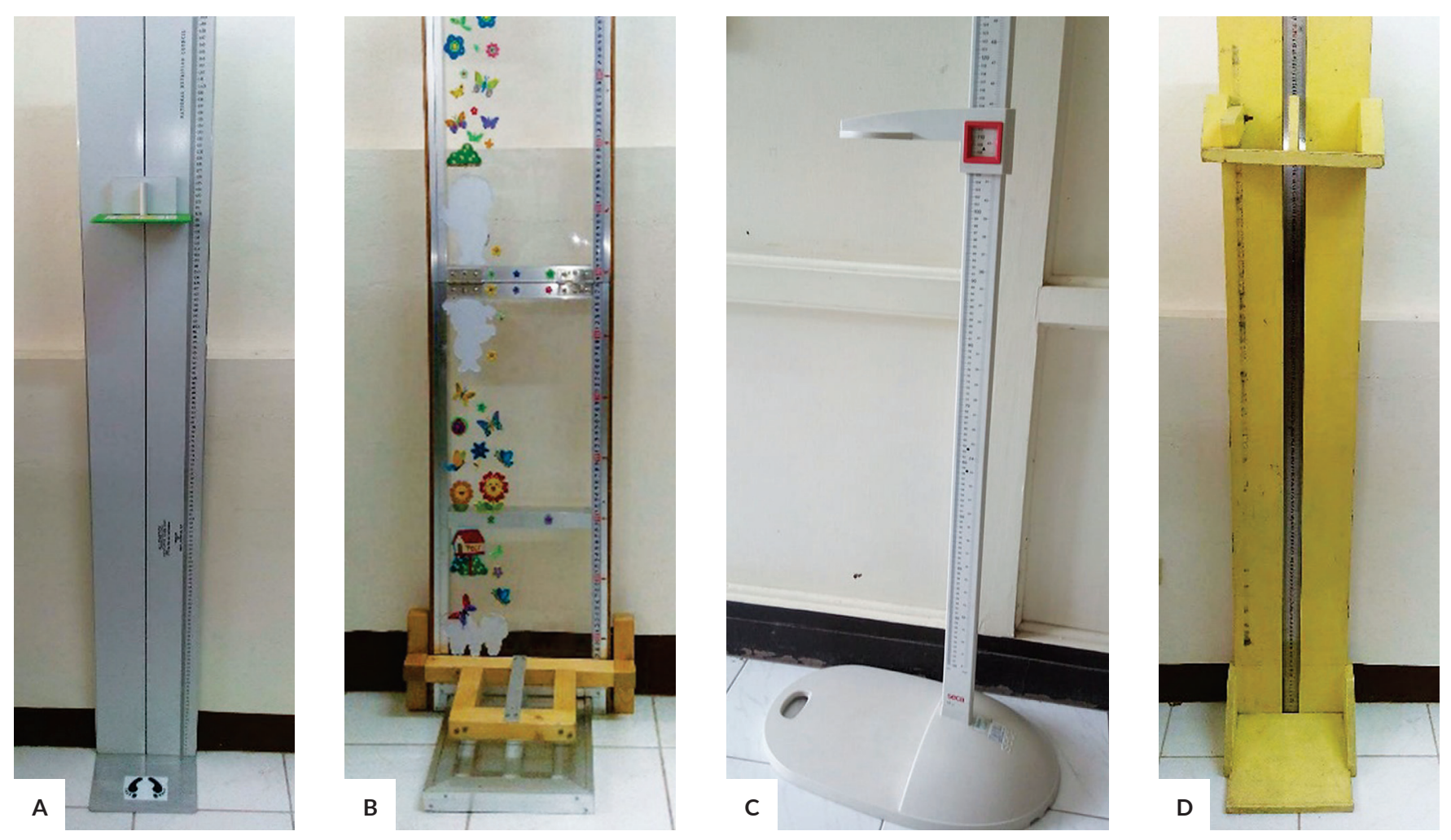

Figure 1. Four various height measuring equipment: (A) Allenstick, (B) Aluminum-Acrylic, (C) Stadiometer, (D) Wooden Height Board.

Table 2. Comparison of mean scores given by CNHWs to four measuring equipment based on various characteristics, Bay and Sta. Rosa, Laguna, Philippines

\begin{tabular}{|c|c|c|c|c|c|}
\hline Characteristic & Allen's stick & $\begin{array}{l}\text { Aluminum- } \\
\text { acrylic HB }\end{array}$ & Stadiometer & $\begin{array}{c}\text { NNC } \\
\text { wooden HB }\end{array}$ & $p^{*}$ \\
\hline Equipment setup & 4.91 & 6.45 & 6.36 & 7.00 & 0.309 \\
\hline Time to verify equipment & 4.36 & 5.91 & 5.45 & 7.45 & 0.112 \\
\hline Ease of reading measurement & 6.09 & 6.67 & 6.08 & 7.08 & 0.473 \\
\hline Time allotted for height measurement & 6.36 & 6.18 & 5.27 & 6.73 & 0.522 \\
\hline Ease of operating the equipment & 6.50 & 6.42 & 5.33 & 7.45 & 0.253 \\
\hline Ease of transporting equipment (based on weight) & 5.92 & 6.42 & 4.42 & 7.33 & 0.208 \\
\hline Perceived safety & 5.50 & 5.58 & 5.25 & 6.92 & 0.417 \\
\hline Parallax & 5.27 & 6.27 & 5.45 & 6.45 & 0.562 \\
\hline Number of hands needed to measure height/length & 6.09 & 5.64 & 5.45 & 6.18 & 0.711 \\
\hline Number of steps to measure height/length & 6.55 & 7.00 & 6.00 & 6.64 & 0.664 \\
\hline Damping (accurately read measurement despite child in motion) & 5.50 & 7.25 & 5.67 & 6.83 & 0.406 \\
\hline Self-contained (number of detached parts) & 3.25 & 7.17 & 5.25 & 6.33 & 0.052 \\
\hline Ease of maintenance & 6.50 & 6.67 & 6.08 & 6.67 & 0.630 \\
\hline Ease of equipment storage & 6.42 & 5.92 & 5.50 & 5.58 & 0.519 \\
\hline Problems encountered in equipment standardization? & 5.75 & 8.13 & 7.25 & 7.38 & 0.482 \\
\hline Problems encountered during height/length measurement & 4.82 & 6.27 & 6.18 & 6.91 & 0.499 \\
\hline Problems encountered in equipment maintenance & 5.27 & 5.73 & 6.09 & 5.55 & 0.733 \\
\hline Problems encountered in equipment storage & 4.55 & 5.36 & 3.91 & 5.82 & 0.236 \\
\hline Likelihood of continuous usage & 7.00 & 6.00 & 5.18 & 5.55 & 0.255 \\
\hline Overall acceptability & 5.24 & 5.96 & 5.22 & 6.18 & 0.333 \\
\hline
\end{tabular}

${ }^{*}$ significant at $p<0.05$

However, the comparison test suggested that scores given to four tools, on average, were not significantly different.

Based on the results of the study, CNHWs from an urban area (Sta. Rosa) favored Allen's stick as the most comfortable equipment to use, mainly because it is lightweight, sturdy, and the graduations are easy to read. Despite the limitation of the stadiometer (it can only measure the height of children 23 months and older), it was still preferred by the CNHWs because they found it easy to use, stable, and lightweight. Alternatively, urban $\mathrm{CNHWs}$ found the aluminum-acrylic $\mathrm{HB}$ as the most difficult to use, since its movable headboard is loose, detachable, and not perpendicular to the height 
board. Meanwhile, CNHWs from a rural area (Bay) found the NNC wooden $\mathrm{HB}$ as the most difficult to use, because it is heavy, bulky, unstable, and inaccurate. Aside from being unappealing to children, the equipment is also perceived to cause injury to the child because of the loose headboard and the pressure generated on the head of the child when securing the lock. Likewise, it has been observed that most of the measurements done with this equipment required a third reading. Considering all the characteristics for equipment evaluation, the CNHWs from urban area recommends Allen's stick to their barangay officials. In contrast, those from rural area recommends stadiometer for height measurement and Allen's stick for length measurement, with the suggestion to improve the fixed footboard, which was deemed too small and thin.

In terms of difficulty in reading the measurement, CNHWs from the rural area found reading the height in the $\mathrm{NNC}$ wooden $\mathrm{HB}$ difficult, since the steel tape is located in the middle of the board in which the child tends to block the reading, and the measurement is read under the headboard obstructed by its shadow. In addition, reading the height measurement was also challenging with the aluminumacrylic $\mathrm{HB}$, as the headboard tends to fall forward because there was no lock to keep it steady. When not placed on flat and even surface, the footboard tends to bend if the child is heavy.

The CNHWs from the rural area also experienced various issues or problems in using the measuring equipment in both study sites. Shared experience in both study sites was the lack of cooperation or support from some parents/ guardians, and the behavior of children (struggling and crying), which made measurements more difficult. The weight of the measuring equipment was also considered a problem, particularly for the NNC wooden HB. Since the stadiometer has detachable parts, end-users were worried that some of its parts might be lost or left behind during data collection proper. Site-specific issues experienced by CNHWs were also noted. In rural area, these include 1) difficulty in measuring length in children unwilling to be measured in supine position, especially when they are moved to the correct position; 2) fear and worry for possibility of hurting the children when pressure is applied on their knees and feet; 3) inability to control the headboard when child struggles, which makes reading measurement difficult.

The CNHWs from the urban area were not confident that they could get an accurate measurement with aluminumacrylic HB since its headboard is loose and not perpendicular to the height board. There was also difficulty in looking for a flat and even surface, where Allen's stick can stand straight.

In terms of maintenance, CNHWs from rural areas expressed that they also maintain, do repairs, and even replace the height board if it can no longer be repaired. However, they were unable to have it verified before use. The above-stated issues or problems were related to the errors committed by the CNHWs, which they have acknowledged.
Alternatively, CNHWs from urban aresa committed errors due to the expected behavior of young children (struggling or crying hard). Also, the recommended protocol in measuring recumbent length using Allen's stick was not observed, resulting in repeated measurement. Some CNHWs misread the measurements when the headboard of the NNC wooden height board moved every time the lock is being engaged.

When asked if the CNHWs will continue measuring height/length of children, those from the rural area stated the importance of identifying the stunted children in order to monitor their growth, and the important use of these data in planning interventions/solutions motivated them to do so. Also, they opined that if the height/length measurement is essential, the height board should be provided for free, or that financial assistance must be provided to purchase the equipment. They also preferred height board equipment not made of wood to avoid damage from termites.

The urban CNHWs, however, expressed their disapproval in doing height measurements. For them, taking the height of children is just an added burden to their already hectic work. One said, "I hope, height should no longer be measured." Another one believed that height is not a logical basis for the nutritional status of the children and even raised the question, "What if being short runs in the family?" Some also insisted that height is determined by genetic inheritance and that nutrition has little contribution to this. Consequently, height measurement was suggested to be removed from OPT plus.

CNHWs in both study sites identified needed support in continuing this work in their communities, such as 1) companion/s who will accompany them when measuring height/length of children, since the equipment is heavy, particularly the NNC wooden $\mathrm{HB}$ and 2) financial aid or allowance for the companion who will accompany them. Some urban CNHWs articulated that there is no need for further support since they are volunteer workers in the first place. Others said that it would be helpful if they will be provided with caps and umbrellas, especially during hot and rainy days. While some barangay captains (village leaders) are supportive, this is not true to all barangays (villages) in urban municipalities. Some CNHWs were also seeking support from their community since there were times that no help and support for their nutrition programs was extended from the barangay chairman.

\section{Parents/guardians' assessment of their expe- riences, measuring equipment and procedures}

All parents/guardians of the randomly selected children from the rural area allowed their children's height/length to be measured by BHW (13.6\%), BNS (22.7\%), pediatrician (9.1\%), daycare teacher (4.5\%), midwife (4.5\%), and nurse (4.5\%). On the other hand, about $62 \%$ of the parents/ guardians from the urban area permitted their children's height/length to be measured by BNS (9.5\%), BHW (38.1\%), pediatrician (14.3\%), and nurse (38.1\%). The children's 
Table 3. Percentage distribution of parents/guardians' experiences in rural and urban study sites, Bay and Sta. Rosa, Philippines

\begin{tabular}{|c|c|c|}
\hline Parameter & Rural (Bay) & Urban (Sta. Rosa) \\
\hline \multicolumn{3}{|c|}{ Allowed their children's height/length to be measured or not } \\
\hline $\begin{array}{l}\text { Yes } \\
\text { Not applicable } \\
\text { Total }\end{array}$ & $\begin{array}{r}100.0 \\
0.0 \\
100.0\end{array}$ & $\begin{array}{r}61.9 \\
38.1 \\
100.0\end{array}$ \\
\hline \multicolumn{3}{|c|}{ Person who measured the height/length of children } \\
\hline $\begin{array}{l}\text { BHW } \\
\text { BNS } \\
\text { Pediatrician } \\
\text { Day care teacher } \\
\text { Midwife } \\
\text { Nurse } \\
\text { Not applicable } \\
\text { No answer } \\
\text { Total }\end{array}$ & $\begin{array}{r}13.6 \\
22.7 \\
9.1 \\
4.5 \\
4.5 \\
4.5 \\
4.5 \\
36.6 \\
100.0\end{array}$ & $\begin{array}{r}9.5 \\
38.1 \\
14.3 \\
0.0 \\
0.0 \\
38.1 \\
0.0 \\
0.0 \\
100.0\end{array}$ \\
\hline \multicolumn{3}{|c|}{$\begin{array}{l}\text { Number of times the BNS/BHW/Others measured children's height/ } \\
\text { length in a year }\end{array}$} \\
\hline $\begin{array}{l}\text { Minimum } \\
\text { Maximum } \\
\text { Mean } \\
\text { Standard Deviation }\end{array}$ & $\begin{array}{r}0.0 \\
12.00 \\
1.36 \\
2.54\end{array}$ & $\begin{array}{r}0.0 \\
12.00 \\
1.19 \\
2.66 \\
\end{array}$ \\
\hline \multicolumn{3}{|c|}{ Parents/guardians informed of their child's height/length } \\
\hline $\begin{array}{l}\text { Yes } \\
\text { No } \\
\text { Not applicable } \\
\text { No answer } \\
\text { Total }\end{array}$ & $\begin{array}{r}31.8 \\
27.3 \\
40.9 \\
0.0 \\
100.0\end{array}$ & $\begin{array}{r}47.6 \\
14.3 \\
28.6 \\
9.5 \\
100.0\end{array}$ \\
\hline \multicolumn{3}{|c|}{$\begin{array}{l}\text { Manner on how information of child's height/length was given to } \\
\text { parents/guardians }\end{array}$} \\
\hline $\begin{array}{l}\text { Verbal } \\
\text { Written in records } \\
\text { Not applicable } \\
\text { No answer } \\
\text { Total }\end{array}$ & $\begin{array}{r}27.3 \\
4.5 \\
68.2 \\
0.0 \\
100.0\end{array}$ & $\begin{array}{r}47.6 \\
0.0 \\
42.9 \\
9.5 \\
100.0\end{array}$ \\
\hline \multicolumn{3}{|c|}{ Informed of their child's nutritional status } \\
\hline $\begin{array}{l}\text { Yes } \\
\text { No } \\
\text { No answer } \\
\text { Total }\end{array}$ & $\begin{array}{r}45.5 \\
54.5 \\
0.0 \\
100.0\end{array}$ & $\begin{array}{r}28.5 \\
66.7 \\
4.8 \\
100.0 \\
\end{array}$ \\
\hline \multicolumn{3}{|c|}{$\begin{array}{l}\text { Manner on how information of child's nutritional status was given } \\
\text { to parents/guardians }\end{array}$} \\
\hline $\begin{array}{l}\text { Verbal } \\
\text { Written in records } \\
\text { Not applicable } \\
\text { No answer } \\
\text { Total }\end{array}$ & $\begin{array}{r}40.9 \\
4.5 \\
54.6 \\
0.0 \\
100.0\end{array}$ & $\begin{array}{r}28.6 \\
0.0 \\
66.6 \\
4.8 \\
100.0\end{array}$ \\
\hline
\end{tabular}

height/length was measured once a year, with some as much as 12 times a year, although the latter is unlikely to happen.

About 32\% (rural area) and 48\% (urban area) of the parents/guardians were informed of their child's height/ length. Around $27.3 \%$ in the rural area and $47.6 \%$ in the urban area received the information verbally. A few in the rural area $(4.5 \%)$ received a written record (Table 3 ). Among parents, the type of material was not a significant factor in measuring the child's height or length. A concern was giving of feedback with regard the results of the measurement. This was similar to the study of Heavy et al. (2017), where Irish parents were generally positive about measuring children. However, concerns such as privacy, embarrassing situations and bullying were raised.

The parents' perspective should be considered since the measurement of height or length will be done yearly as part of the growth monitoring or OPT. Mothers have to be reassured about the health of their children. ${ }^{11}$ In a study in South Africa, mothers were reassured by nutrition monitors about their children's growth curves. The systematic review of Roberfroid et al. (2005) on growth monitoring, while it focused on weight measurement, revealed that the test or measurement should be acceptable to caretakers and that there are not many studies on this topic.

The safety of the equipment that will be used in measuring the height/length of children is also among the major concerns of parents/guardians. Hence, they were asked about their opinion on the four measuring tools based on specific characteristics. Table 4 shows $50 \%$ of parents/ guardians in rural areas considered aluminum-acrylic $\mathrm{HB}$ and NNC wooden HB appearance non-threatening. Conversely, $57.1 \%$ of urban parents/guardians found Allen's stick and aluminum-acrylic HB appearance non-threatening.

In terms of cultural acceptability of having a 0-2 years old child lie down to measure recumbent length, many parents/guardians from both areas found aluminum-acrylic $\mathrm{HB}$ and Allen's stick to be acceptable. The majority of those from the rural area (59.1\%) considered aluminumacrylic $\mathrm{HB}$ as the safest tool, while those from the urban area chose Allen's stick (71.4\%). Moreover, Allen's stick was found by many parents/guardians (both areas) as the tool with a more comprehensible measurement procedure. Also,

Table 4. Percentage distribution of height/length measuring equipment tools preferred by parents/guardians, Bay and Sta. Rosa, Laguna, Philippines

\begin{tabular}{|c|c|c|c|c|c|c|c|c|}
\hline \multirow{2}{*}{ Characteristic } & \multicolumn{2}{|c|}{ Allen's stick } & \multicolumn{2}{|c|}{ Aluminum-acrylic HB } & \multicolumn{2}{|c|}{ Stadiometer } & \multicolumn{2}{|c|}{ NNC wooden HB } \\
\hline & Rural & Urban & Rural & Urban & Rural & Urban & Rural & Urban \\
\hline Non-threatening appearance & 36.4 & 57.1 & 50.0 & 57.1 & 18.2 & 38.1 & 50.0 & 23.8 \\
\hline $\begin{array}{l}\text { Cultural acceptability of having } 0-2 \text { years } \\
\text { old children lie down to measure } \\
\text { recumbent length }\end{array}$ & 54.5 & 42.9 & 54.5 & 61.9 & 0.0 & 19.0 & 50.0 & 28.6 \\
\hline Perceived safety of the equipment & 45.5 & 71.4 & 59.1 & 42.9 & 22.7 & 38.1 & 36.4 & 14.3 \\
\hline $\begin{array}{l}\text { Comprehensibility of height/length } \\
\text { measurement procedure }\end{array}$ & 59.1 & 66.7 & 54.5 & 33.3 & 13.6 & 33.3 & 36.4 & 33.3 \\
\hline Child comfort & 36.4 & 61.9 & 72.7 & 42.9 & 13.6 & 33.3 & 22.7 & 14.3 \\
\hline
\end{tabular}


aluminum acrylic $\mathrm{HB}(72.7 \%)$ and Allen's stick (61.9\%) were observed to be the most comfortable tool in the rural and urban areas, respectively. Thus, considering all the characteristics mentioned, it can be said that rural parents/ guardians preferred aluminum-acrylic $\mathrm{HB}$, while urban ones preferred Allen's stick.

\section{CONCLUSION AND RECOMMENDATIONS}

The preference of CNHWs and parents/guardians differed. Among the CNHWs, result of the focus group discussion revealed a preference for the stadiometer for height measurement and Allen's stick for length measurement. However, a comparison of the four tools signified that the scores given were not significantly different. Among parents/ guardians, aluminum-acrylic $\mathrm{HB}$ and Allen's stick were the preferred measuring equipment, as these were found to be non-threatening, were culturally acceptable, perceived to be safe, facilitated ease of use among children being measured, and the procedures were easy to understand.

\section{Statement of Authorship}

All authors participated in the data collection and analysis and approved the final version submitted.

\section{Author Disclosure}

All authors declared no conflicts of interest.

\section{Funding Source}

Council.

\section{REFERENCES}

1. Gibson R (2005). Principles of Nutritional Assessment, 2nd edition. Oxford University Press, Inc, New York.

2. von Hinke S, Scholder K, Smith GW, Lawlor DA, Propper C \& Windmeijer F (2013). Child height, health and human capital: Evidence using genetic markers. European Economic Review 57:1-22. https://doi.org/10.1016/j.euroecorev.2012.09.009.

3. Louer AL, Simon DN, Switkowski KM, Rifas-Shiman SL, Gillman MW \& Oken E (2017). Assessment of child anthropometry in a large epidemiologic study. J Vis Exp. 2017; (120): 54895.

4. Wells JCK, Stocks J, Bonner R, Raywood E, Legg S, Lee S, Treleaven P \& Lum S (2015). Acceptability, Precision and Accuracy of 3D Photonic Scanning for Measurement of Body Shape in a MultiEthnic Sample of Children Aged 5-11 Years: The SLIC Study. PLoS ONE 10(4): e0124193.https://doi.org/10.1371/journal.pone.0124193.

5. Heavey PM, McMahon O, McConnon A, O'dwyer U, Hayes C, Eldin N \& Kelleher C (2013). Childhood nutrition and obesity: current status and future challenges Parents' attitudes and acceptability of anthropometric measurement of Irish school children. Proceedings of the Nutrition Society 72(OCE3): E144. doi:10.1017/ S0029665113001675.

6. Roberfroid D, Kolsteren P, Hoerée T \& Maire B (2005). Do growth monitoring and promotion programs answer the performance criteria of a screening program? A critical analysis based on a systematic review. Tropical Medicine \& International Health 10:1121-1133. doi:10.1111/j.1365-3156.2005.01498.x.

7. National Nutrition Council (2012). Implementing Guidelines on Operation Timbang Plus (OPT +). Inter-agency Technical Working Group on Child Growth Standards Approved for nationwide implementation by the NNC Governing Board pursuant to NNC Governing Board Resolution No. 2, Series 2012. NNC Governing Board, Philippines.

8. National Nutrition Council Governing Board Resolution No. 2, Series 2012 (2012). NNC Governing Board, Philippines.

9. World Health Organization (2008). Training Course on Child Growth Assessment. WHO, Geneva.

10. La Fave D \& Duncan T (2017). Height and cognition at work: Labor market productivity in a low income setting. Econ Hum Biol. 2017 May; 25: 52-64. https://doi.org/10.1016/j.ehb.2016.10.008.

11. Faber M, Phungula MAS, Kvalsvig JD, Benadé AJS \& Young H (2003). Acceptability of community-based growth monitoring in a rural village in South Africa. Food Nutr Bull 2003 Dec;24(4): 350-9. doi: 10.1177/156482650302400405. 